\title{
Management of logistics chains of industrial enterprises in high-tech industries
}

\author{
Alexander Demchenko ${ }^{1, *}$, and Yulia Astashova ${ }^{1}$ \\ ${ }^{1}$ South Ural State University (National Research University), Department of Marketing, Chelyabinsk, Russia
}

\begin{abstract}
The article analyses the trends of high-tech industries development in the market globalization conditions. The economic growth of high-tech industries largely depends on technological innovations, products and equipment based on usage of the results of applied and fundamental scientific researches. It is shown that characteristics of high-tech productions influence the logistics chain structure. It justifies the importance to include partnering enterprises taking part in creation of intellectual and tangible assets in the logistic chain of the industrial enterprise. It is noted that development of production technologies contributes to formation of innovative logistic chains, which participants are enterprises cooperating for achievement of competitive power. The article offers a model of an industry logistic chain comprising the conventional logistic chain and innovative logistic chains corresponding to the industry market segments. It is proposed to use the customer value of the manufactured products as a criterion of the industrial enterprise's logistic chains management efficiency. Implementation of the offered model of cooperation between the logistic chain participants is aimed at creation of a continuous innovations flow, reduction of technological development costs and uniting of the participants' experience.
\end{abstract}

\section{Introduction}

In economic globalization conditions more and more Russian enterprises face the necessity to review their key economic management principles. In the Russian economic structure there appear industries, in which business operations carried out by independent participants are associated with several challenges or almost impossible. We can note a tendency of a transition from the competition between market players to the competition between associations of partners or holdings controlling the key stages of product development, production and market promotion.

Formation of a stable partner cooperation system has acquired a discrete role in high-tech industries, where the main success factor is product development competence.

High scientific and technical development rates, ever-increasing share of $R \& D$ costs, uncertainty of the demand and terms of production of high-tech goods precondition the need for cooperation of the industry market players to unite the available resources and improve the competitive power.

\section{Topicality of the problem. Literature review}

The issues of an efficient management of industrial enterprises' logistics chains have been considered in different enterprise management fields, such as general and strategic management, logistics and innovation management.

One of the up-to-date approaches to business operations is integrated supply chain or logistics chain management. The Supply Chain Management (SCM) concept, which was initially formed in the disciplinary sphere of logistics, currently represents a separate field of knowledge. The SCM concept is based on the fact that the manufacturing enterprise is not a formation independent of the environment but a part of a system chaining "sources of raw materials - production shipment to the end user".

Term "Supply Chain Management" was introduced for scientific researches in 1983 and became widespread in 1999 after publication of the work of Robert B. Handfield and Ernest L. Nichols [1]. Later the SCM concept was further developed in the works of Donald J. Bowersox [2, 3], Martin Christopher [4], Robert B. Handfield [5], Douglas M. Lambert [6, 7], James R. Stock [8]. It is shown in the works of these authors that the SCM concept is based on the problems of business process management, integration of partners, introduction of information control systems, which is particularly important in the economic globalization conditions.

The SCM concept has been dynamically developed by the Russian schools of science. The works of Russian scientists systematize basic theoretical provisions of the SCM [9-11], develop applied elements of the theory [12, 13], study aspects of functional management within the

\footnotetext{
Corresponding author: aidchel@mail.ru
} 
framework of the SCM [14-16] and issues of integration in the chains [17-19].

In spite of the in-depth development of a wide range of issues, it should be noted that logistics chain management in the industries connected with R\&D and innovative activities has been studied rather fragmentarily yet. The most important task for organization of innovative production structures is building of value chains with an organized cooperation of developers, suppliers and consumers aimed at creation of innovations.

High-tech enterprises are enterprises, which operations result in products (goods, works, services) with a considerable added value obtained at the cost of application of scientific, technical and technological achievements, characterized by a high share of R\&D costs.

Peculiar features of high-tech products are also reflected in the logistic chain structure, which must permanently integrate participants implementing R\&D. We believe that presence of such participants modifies the logistic chain structure. Alongside with the main production cycle of the participants' cooperation, the second cycle is formed, which is connected with development and diffusion of innovations and R\&D results and which covers one or several links of the production cycle.

Thus, in the conditions of the targeted transition of Russia to the high-tech economic structure, the approaches to the logistics chain formation and management in high-tech industries are subject to indepth development.

\section{Statement of research objectives}

The research objective is justification of the structure and development of approaches to industrial enterprises' logistics chain management in high-tech industries.

The industrial enterprise's logistics chain structure in a high-tech industry must consider cooperation with partnering enterprises for joint development and use of intellectual and tangible assets, manufacture and sales of high-tech products in the market conditions.

\section{Key research findings}

One of the key factors determining adaptability of industrial enterprises is the innovative potential - ability to manufacture innovative products with application of up-to-date production processes, which will allow to ensure competitiveness on the international market.

The noted tendencies of economic openness and globalization are particularly typical of high-tech product markets. These industries are characterized by integration of separate enterprises in order to increase their performance efficiency.

Subject to the international classification, high-tech industries include industries, in which R\&D costs comprise at least $10 \%$ of the added value and the labor costs for scientists, engineers and technicians exceed $10 \%$ of the total labor costs.
The complex of high-tech economic sectors includes: aerospace industry, radioelectronics, production of computers, office equipment and software, as well as communication means, medical equipment, precision and optical-electronic equipment, chemical and pharmaceutical industry. The defense industry complex, which has a vast scientific-technical and industrial potential, occupies a special place.

Subject to the classification of the Organization for Economic Cooperation and Development (OECD), two approaches are used to define high-tech industries.

- Classification by the high-tech sectors. In this case the criterion is intensity of application of up-to-date technologies in the course of production.

- Classification by the product. In this case the criterion of affiliation with a high-tech industry is the end product and its research intensity.

Goods of high-tech industries are characterized by the following features: uncertainty of demand; creative approach to application; developed copying practice; blurred competitive environment. The life cycle of products is short, whereas appearance of such products at the competitors liquidates the enterprise's competitive advantage.

The economic growth of high-tech industries largely depends on technological innovations, products and equipment, which contains progressive knowledge [20,21].

Thus, the key success factor in these industries is product development competence. Consequently, the manufacturing enterprise has to form its own product development and design base or to search for efficient partners in this sphere. The efficiency of partnership in the conditions of a short product life cycle is determined by the development rates, duration of the product launch cycle and flexibility of processes.

It is also necessary to consider that researches and developments at high technology change rates are associated with a high investment risk. They include: indefiniteness of the terms of researches and associated costs, necessity to solve scientific and technical problems, use of unique resources, absence of a forecasting base.

In this connection, the variant of cooperation between the participants is deemed more expedient. Within the framework of the logistic chain formation procedure special attention must be paid to risk distribution between the partners.

In order to mitigate the chain's risks in this sphere cooperation of the participants is characterized by an average integration degree or presence of the chain link of a developer ensuring a high product updating rate. The ability to assume the chain's risks defines the enterprise's position in the logistics chain and its ability to influence other participants of the chain and to make the chain management decisions.

At working out of the manufacturing enterprise development plan in high-tech industries it is necessary to draw attention not only to product development but also to technological development and updating, which is impossible without major investments. 
Therefore, we can conclude that for a manufacturing enterprise of a high-tech industry, which lacks a developed base for independent developments, the toppriority task is formation of partner links with enterprises able to conduct R\&D or having developments but lacking their own production assets. The manufacturing enterprises' need for cooperation with enterprises developing innovative products and technologies is confirmed by the following data: the volumes of R\&D outsourcing have shown a stable growth since the 80 s of the XXth century, by the beginning of the XXI century they rose beyond the mark of $10 \%$ and currently comprise $15 \%$ [22].

The success in the sales link of the supply chain largely depends on the level of marketing project preparation at the $\mathrm{R} \& \mathrm{D}$ elaboration and commercialization stage. Meeting of the customers' needs and expectations, as well as competitive power of the manufactured products allow to form a structure of the product sales participants, which ensures availability and accessibility of the products.

Thus, analysis of the market needs and evaluation of the ability to gain profit from the sales of high-tech products is one of the key technological development factors.

Analysis of the key success factors in the manufacturing enterprise structure assumes identification of common industry parameters, which implementation allows to improve the competitive position on the market. The key success factors in the production sphere include high quality of the manufactured products, low production costs and its planning, strong links with suppliers, qualified work force, advantageous location, etc.

Then, for understanding of the own competitive advantages it is necessary to analyze companies working in this sphere. It is necessary for formation of mutually beneficial cooperation offers to the potential partner. In the conditions of technological depreciation the search of potential partners must by anticipatory, for which purpose the enterprise must have a clear idea of the partners to cooperate with, the advantages, which can attract potential partners to cooperation, and the forms of cooperation, which are most acceptable.

An efficient form of cooperation is inter-company cooperation, when the enterprises' resources, competences and basic technologies are united to achieve a better result. The competition and a high share of R\&D costs force the companies to carry out parallel innovative activities with regard to products, implemented processes, organization and management. According to the researches, business-to-business cooperation increases the companies' innovative performance [23].

It is noted that the outlined high-tech industries have a higher level of innovative activities. They, in particular, have higher values of the following indicators: intensity of innovation costs; specific weight of employees engaged in researches and developments; share of new goods in the total volume of the shipped products; specific weight of organizations taking part in joint projects; share of the federal budgetary funds in the sources of innovation cost financing.

Analysis of the conventional supply chain structure within the framework of the industry high-tech product market allows to outline the following interacting links: R\&D works; design engineering; procurement; production; sales and distribution.

At the junction of separate links the following industry markets are formed: market of $R \& D$ results, market of design engineering works, production equipment market, high-tech product market. The above markets differ by the degree of innovative activities, duration of the life cycle of the manufactured products, copying capabilities, competition level, etc.

Thus, the activity of manufacturing enterprises of high-tech industries leads to formation of an industry logistics chain consisting of the conventional logistic chain and innovative logistic chains corresponding to the segments of the industry market, namely:

- Scientific researches.

- Design engineering.

- Development of industrial technologies (applied researches).

- Manufacture of high-tech products.

- Promotion and sales of high-tech products.

Cooperation of the conventional and the forming innovative logistic chains is shown in Fig.1.

It should be noted that development of industrial technologies includes implementation of applied researches, as well as investment activities ensuring manufacture of products.

The degree of the customers' evaluation of the manufactured products is determined by taking of actions needed for development, production, supply and support of the product. Thus, the value of the products manufactured by the enterprise is characterized by the quality of the supplied good, its conformity with the customers' needs and expectations, as well as the quality of the accompanying service.

The objective of the logistics chain management is creation of the industrial enterprise's value chain, which is more efficient as compared to the competitors. The contribution in adding value of individual processes, structures of the enterprise, as well as its partners generally differs significantly.

Let us consider the value of manufactured products $V$. Then, it follows from Fig. 1 that

$$
V=f\left(v_{\mathrm{i}}, w_{\mathrm{ij}}\right)
$$

where $v_{\mathrm{i}}-$ value added by activity $i$ within the framework of the conventional logistic chain; $w_{\mathrm{ij}}$ - value added at the $j$-th section of the formed innovative logistic chain corresponding to activity $i$. 


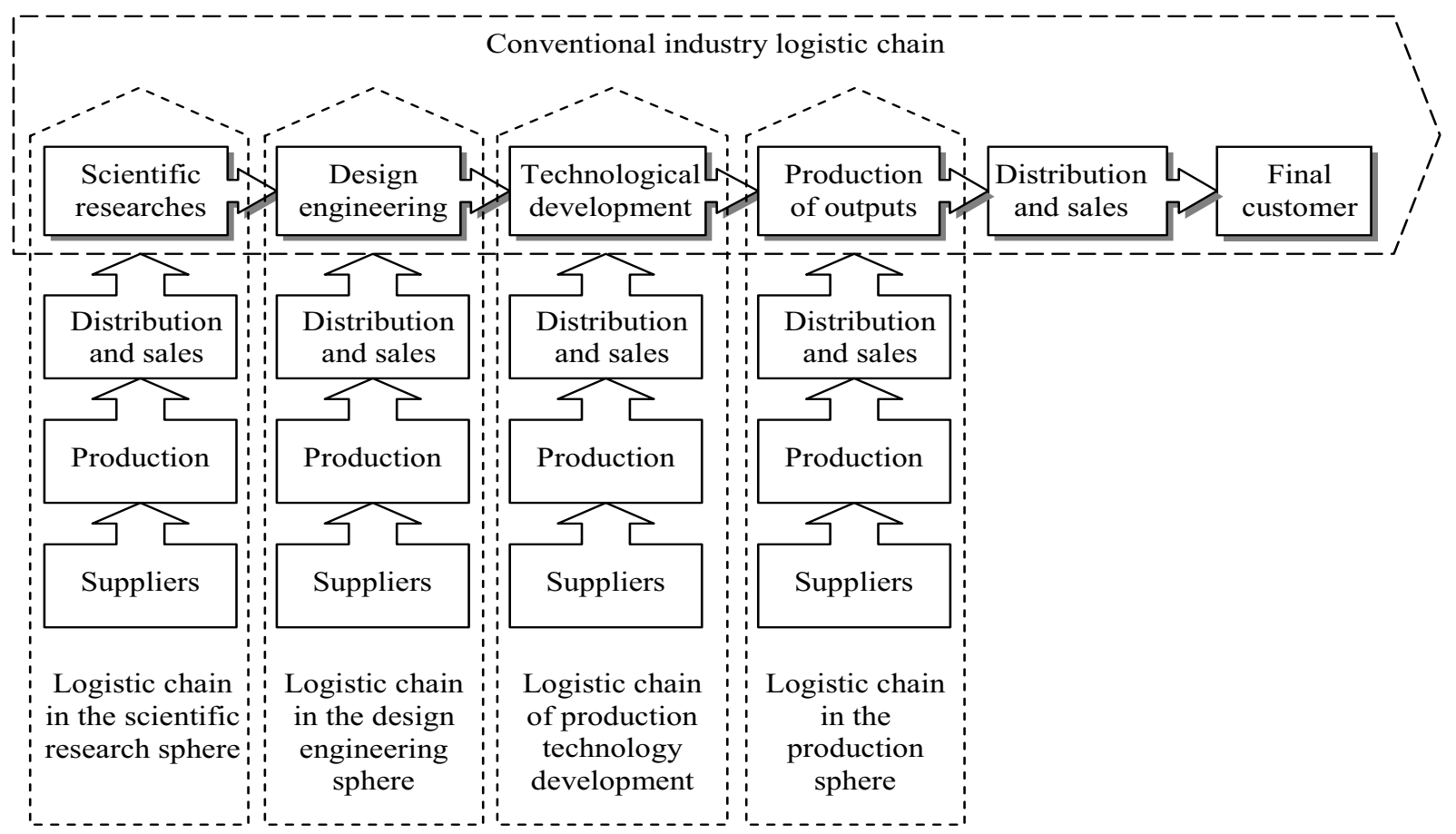

Fig. 1. Logistics chain model of high-tech industries.

Implementation of a specific organizational form of economic entities' integration within the framework of the logistics chain depends on the integration degree, as well as the associated risks. In this connection, the most appropriate way is integration based on business processes. Its applicability is determined by implementation of the process approach to enterprise management. Organization of activities based thereon allows to solve several most important tasks, including optimal resource management, minimization of nonproduction costs, as well as compliance with the needs of all groups of customers.

Use of information systems at modeling and control of the key process parameters allows to integrate the enterprise in the process logistics chain system by reconciliation of the own processes with the partners' abilities and demands, which gives advantages in the joint resource allocation, response to internal and external environmental changes and mutually beneficial coordination of activities on adding customer value of high-tech products.

\section{Conclusions}

The offered structure of the industrial enterprise's logistics chain management considers cooperation of the high-tech product market players aimed at increase of their competitive power.

The strong points of formation of enterprises' logistic chains comprising both conventional and innovative chains include:

- Creation of a continuous flow of innovative concepts and developments.
- Reduction of technological development costs (currently only one fourth of the patented technologies created inside enterprises is implemented).

- Uniting of the experience of the supply chain participants at development and commercialization of high-tech products.

The work was supported by Act 211 Government of the Russian Federation, contract № 02.A03.21.0011.

\section{References}

1. R.B. Handfield, E.L. Nichols, Introduction to Supply Chain Management (Prentice Hall, New Jersey, 1999)

2. D.J. Bowersox, D.J. Closs, Logistical Management: The Integrated Supply Chain Process (McGraw-Hill Companies, 1996)

3. D.J. Bowersox, D.J. Closs, M.B. Cooper, Supply Chain Supply Management (McGraw-Hill, 2013)

4. M. Christopher, Supply and Supply Chain Management (Financial Times/Pearson Education, 2016)

5. R.B. Handfield, E.L. Nichols, Supply Chain Redesign: Transforming Supply Chains Into Integrated Value Systems (Prentice Hall, New Jersey, 2002)

6. D.M. Lambert, Supply Chain Management: Processes, Partnerships, Performance (SCMI, Sarasota, 2008) 
7. D.M. Lambert, The Supply Chain Management and Logistics Controversy (Pergamon Press, Oxford, 2001)

8. J.R. Stock, D.M. Lambert, Strategic Logistics Management (McGraw-Hill, New York, 2001)

9. D.A. Ivanov, Supply Chain Management (Polytechnic University, Saint Petersburg, 2009)

10. V.I. Sergeev, Logistics and Supply Chain Management, 5(16), 6 (2006)

11. Y.V. Fedotov, K.V. Krotov, Russian Management Journal, 9, 49 (2011)

12. V.S. Lukinsky, O.V. Badokin, T.A. Blazhenkova, A.A. Bochkarev, E.I. Zaitsev, V.V. Lukinsky, Problems of Formation of the Applied Theory of Logistics and Supply Chain Management (SPSUEE, Saint Petersburg, 2011)

13. O.D. Protsenko, Logistics, 4, 30 (2013)

14. A.G. Butrin, E.I. Rogozhnikov, V.I. Tsaplin, Economic Analysis: Theory and Practice, 15, 30 (2010)

15. V.V. Lukinsky, T.A. Kulagovskaya, Y.V. Malevich, Bulletin of Saint Petersburg State University of
Engineering and Economics. Series: Economics, 1, 217 (2009)

16. A.N. Sterligova, Logistics and Supply Chain Management, 4(9), 36 (2005)

17. V.V. Dybskaya, E.I. Zaitsev, V.I. Sergeev, A.N. Sterligova, Logistics. Integration and Optimization of Logistical Business Processes in Supply Chains: MBA manual (Exmo, Moscow, 2008)

18. V.S. Lukinsky, V.V. Lukinsky, T.G. Shulzhenko, Logistics and Supply Chain Management, 4(57) (2013)

19. L.B. Mirotin, A.G. Nekrasov, Logistics of the Integrated Supply Chains (Ekzamen, Moscow, 2003)

20. S.Y. Glazjev, Nanotechnologies as a Key Factor of the New Technological Structure in the Economy (Trovant, Moscow, 2009)

21. E.N. Kablov, Science and Life, 4 (2010)

22. E.N. Gorlacheva, I.N. Omelchenko, Science and Education, 12, 1 (2010)

23. V.S. Verba, E.N. Gorlacheva, A.G. Gudkov, Innovations, 3(149), 56 (2011) 